\title{
Introduction: Examined Live - An Epistemological Exchange Between Philosophy and Cultural Psychology on Reflection
} AQ1

Waldomiro J. Silva Filho 1

Luca Tateo 1⿴囗十

Emailluca@hum.aau.dk

Felipe R. L. Santos 2

1 Faculdade de Filosofia e Ciências Humanas, Federal University of Bahia, Bahia, Brazil

2 CONCEPT (Cologne Center for Contemporary Epistemology and the Kantian Tradition), Universität zu Köln, Cologne, Germany

\section{Abstract \\ $\mathrm{AQ2}$}

The abstract is published online only. If you did not include a short abstract for the online version when you submitted the manuscript, the first paragraph or the first 10 lines of the chapter will be displayed here. If possible, please provide us with an informative abstract.

Since the famous passage in which Socrates (Plato 1997) says that the unexamined, and therefore nonreflected, life is not worth living, "reflection" has been a diffuse and iterant term in ethics, moral philosophy, epistemology, political philosophy (Tiberius 2008; Skorupski 2010), but also in psychology (Marsico et al. 2015). This volume opens a new perspective on the topic of reflection, considering the most recent approaches in both philosophy (namely in epistemology) and cultural psychology.

\section{Keywords}

Reflection

Virtue epistemology

Cultural psychology

Agency

Understanding

\subsection{Introductory Remarks}

Since the famous passage in which Socrates (Plato 1997) says that the unexamined, and therefore non-reflected, life is not worth living, "reflection" has been a diffuse and iterant term in ethics, moral philosophy, epistemology, political philosophy (Tiberius 2008; Skorupski 2010), but also in psychology (Marsico et al. 2015). This volume opens a new perspective on the topic of reflection, considering the most recent approaches in both philosophy (namely in epistemology ${ }^{1}$ ) and cultural psychology. 
There is an uncontroversial epistemic sense of "reflection" as the act of understanding that enables the formation of ideas which cannot be directly obtained from external things via empirical experience. This definition covers the acts of the person who allows herself to think, doubt, and compare her own psychological states and actions. Kornblith (2002) recognizes that reflecting on one's own belief is characteristic of human life:

We sometimes wonder whether the beliefs we have are ones we ought to have. And we sometimes wonder about beliefs we might come to adopt, whether we ought to adopt them. More than this, such reflection does not seem, at least typically, to be an idle academic exercise. (Kornblith 2002, p. 103)

In everyday life, we have thoughts whose objects are neither observed things or events nor other people's accounts, but our own beliefs or actions. In this sense, "reflecting" is a common mental activity.

The acknowledgement of the ordinary capability to consider our own psychological states and our own actions can lead to a more problematic (controversial) and stronger thesis: reflection is a condition for being human (moral and epistemic) agents. In fact, for a broad tradition, "reflection" is a term frequently associated with the admirable and valuable search for moral and epistemic clarity and to the meaning of human agency. Even though we share with other animals the capability of simple actions (e.g. to act according to first-order beliefs and desires, like dogs or whales), the "exercise of human agency consists in judgment and behavior ordered by selfconscious reflection about what to think and do" (Doris 2015, p. x). In moral philosophy, for instance, many philosophers think that morality of human action is the outcome of free will of a subject able to reflect about her own desires and beliefs (Frankfurt 1971). They also think that the capability of reflective access to one's own beliefs, desires, motivations etc. is essential to the possibility of moral deliberation and freedom of action (Korsgaard 1996). In epistemology, many philosophers claim that only an agent provided with the capability to forming second-order beliefs by reflection can justify and warrant her beliefs, after examining and testing her own first-order states (first-order beliefs and desires) and to know in the relevant sense (Chisholm 1973; Bonjour 1985; Sosa 2007).

As we know, we usually form beliefs unreflectively and we act unreflectively in virtue of our involvement with the natural and social world around us. It is of course common that, during the process of first-order beliefs formation, we are subject to errors, biases, and unreliable sources of information. These risks affect our capability of achieving the truth or acting in a correct way. For these reasons, for many thinkers, to give up examining the process of beliefs formation and their contents is "to neglect the pursuit of truth" (Bonjour 1985, p. 8). To accept a belief that has not been reflectively examined "is, one might say, epistemically irresponsible" (Bonjour 1985, p. 8), as well as morally irresponsible (Korsgaard 2008, p.100). In this sense, a reflection would have a direct and necessary relation with the nature and the life as rational beings. According to this perspective, there is a rational agent if there is someone who has justified belief, and acts justifiably, because has a selfconscious perspective about her own beliefs and acts. Only a self-critical reflection can provide such a condition, and it would be lacking in "mere animals" (McDowell 1994, pp. 108-126; Frankfurt 1999, pp. 105-106).

AQ4

This is why the notions of reflection and agency have walked together. In general, one talks about epistemic agency when a person consciously stops, reflects and questions herself about what she has to believe or to do. In this case, an agent would be the one who, after performing an evaluation of her own states, is able to assess the reliability of her own epistemic or practical performance, to give credit to her own beliefs, and become responsible for her own actions. We no longer merely have beliefs and are only aware of those beliefs. Once the reflection allows us to distance ourselves from our own mental states and put them in question (Korsgaard 1996, p. 93), we turn into an agent towards our own beliefs and actions. The reflexive character of human understanding implies the question of the normativity of agency. We turn our attention towards ourselves, our own internal states, and we become self-conscious of our own intentions, desires, beliefs, attitudes and of the way those states have been formed (Nagel 1996, p. 200).

\subsubsection{Taking Reflection Seriously}


However, according to other philosophers, the supposed capability of accessing, controlling, evaluating and deciding about one's own beliefs; as well as the capability of producing new beliefs based exclusively on reflection; and the capability of acting on the basis of reflexive self-consciousness, is a mere illusion, or something at least very limited (Goldman 1979; Tiberius 2008; Kahneman 2011; Kornblith 2012; Engel 2013; Hieronymi 2014; Proust 2013; Doris 2015). ${ }^{2}$ There is an intense debate around the disagreement about the place and value of reflection in the cognitive and moral human economy.

What exactly is at stake, here? In fact, the philosophical dispute about the nature and value of reflection revolves around a family of arguments that generally include at least one of the following six aspects:

(i) the issue of epistemic accessibility: epistemic accessibility asserts that for a person to be epistemically justified in having a belief, it is not sufficient for this belief to be true (this is, in fact, necessary, but not sufficient). In addition, it must be possible that they can become aware by reflection of the reasons that guarantee that this belief is true;

(ii) the issue of epistemic voluntarism: a strong voluntarism about our doxastic states usually defends that when we reflect, our beliefs are typically formed by means of a decision and our knowledge of our own beliefs is explained by the fact that we decide what to believe in and not because of something that we discover about our minds;

(iii) the skeptical issue of justification: if an individual sustains the belief that $p$ and not the belief that $\neg p$, she must have a reason for it. If the individual declares that she has such a reason, then we may ask her to present it, and to defend it against the three objections: infinite regress (where the reason refers to another reason which, in turn, refers to another reason, ad infinitum); vicious circularity (where this reason is sustained on a previously presented reason), and; arbitrary assumption (where the reason is not sustained on anything);

(iv) the issue of the principle of epistemic responsibility: for many actors epistemic justification is the essential relationship between the individual and the consequences of their belief and, in this sense, accepting a belief in the absence of such reason is epistemologically irresponsible. Hence, reflection appears to be a necessary condition for the revision of our reasons and for epistemic responsibility;

(v) the issue of overintellectualization: from an internalist perspective (which tends to over intellectualize our cognitive activities), knowledge attribution seems to be rare (there are only a few cases of people knowing/finding out about something because they reflect, find reasons and justify their beliefs) when people are able to intellectually examine their own performances and cognitive achievements;

(vi) the issue of luminosity: luminosity refers to the requirement that an individual is not only able to know that $\mathrm{p}$ (first-order thought), but also - and mainly - to know that they know that $\mathrm{p}$ (second-order thought) by reflection.

In the current debate, these points may appear separate or combined.

This is not a mere scholastic debate. An eloquent example of the relevance of this subject lies in psychology, which is caught into an epistemological paradox. Although it is considered that one's own psychological experience is only accessible through introspection (Bühler 1907/1999), scientific psychology only admits knowledge built through intersubjective means. Basically, the knowledge about one's own psychological experiences (thoughts, emotions, etc.) has no epistemic value in psychology, unless it is validated through an intersubjective procedure or method (measuring, interviewing, testing, scanning, etc.) mediated by an apparatus (tests, items, fMRI, etc.). The mediation of external elements is considered crucial for "reflection to be reliable and valid is an anchor point in a "reality" that is accessible to others for critical discussion." (Van SeggelenDamen et al. 2017, p. 794). 
The question is complicated also by the fact that reflection has not only to do with thinking, but with all the psychic processes and even with action. This is why "reflection" is often referred to as a "fuzzy" term in psychology (Van Seggelen-Damen et al. 2017). It can refer to self-perception, to meta-cognition, to emotion regulation, but also to self-efficacy and self-assessment (Dunning 2005). When it refers to action or practices, especially professionals reflecting on their own practices, it is often called "reflexivity" (Marsico et al. 2015). This complexity is also caused by the fact that a large part of psychology has agreed to separate the different psychic processes (emotion, cognition, reflection, perception, imagination, etc.) not only for analytical purposes, but giving them a different ontological status. So, it becomes problematic when one needs to account for the content of any psychic act: what is the "composition" of such an act? Is it more cognition, or more emotion? Does it exist an act, which is a pure product of a single process (e.g. a pure act of cognition)?

We started from quiet waters (to a trivial affirmation of which we have the capacity to reflect), and, with only a few strokes, we arrive in turbulent waters ...

\subsection{What Is the Nature, Cognitive Role and Epistemic Value of the Reflective Scrutiny?}

Besides the general agreement about the human capability of reflection, there is a large area of disagreement and debate about the nature and value of "reflective scrutiny" and the role of "second-order states" in everyday life. This problem has been discussed in a vast and heterogeneous literature about topics such as epistemic injustice, epistemic norms, agency, understanding, meta-cognition etc. However, there is not yet any extensive and interdisciplinary work, specifically focused on the topic of the epistemic value of reflection. This volume is one of the first attempts aimed at providing an innovative contribution, an exchange between philosophy, epistemology and psychology about the place and value of reflection in everyday life.

Our goal in the next sections is not to offer an exhaustive overview of recent work on epistemic reflection, nor to mimic all of the contributions made by the chapters in this volume. We will try to highlight some topics that have motivated a new resumption of this field and, with that, drawing on chapters from this volume where relevant.

Two elements defined the scope and content of this volume, On the one hand, the crucial contribution of Ernest Sosa, whose works provide original and thought-provoking contributions to contemporary epistemology in setting a new direction for old dilemmas about the nature and value of knowledge, giving a central place to reflection (Greco 2004; Turri 2013; Bahr and Seidel 2016) (it will be developed in 2.1). On the other hand, the recent developments of cultural psychology, in the version of the "Aalborg approach" (Valsiner et al. 2016), reconsider the object and scope of psychological sciences, stressing that "[h]uman conduct is purposeful" (Valsiner 2015, p. 80). This theoretical shift implies as consequence that psychology should take into account how:

the conduct is constructed by goals-oriented agents (persons) who posit a future state of possible affairs and then proceed to construct it (...). Agency is a necessary starting point for understanding human conduct-there is no structure of any human invention-external or internal (subjective) - without its maker. (Valsiner 2015, p. 80).

The object of psychological sciences becomes the phenomena of collectively coordinated, personally meaningful conducts. In this sense, any product of human activity, from art to food production, from child rearing to mediation, from killing to architecture, becomes a legitimate arena for the study of psychological experience. Every human production is at the same time unique, as the result of purposeful action in a given time/space, and collectively coordinated, as it is both the producer and the product of human history in the irreversible flowing of time (it will be developed in 2.1).

These two independent perspectives do not cover of course the whole of the current debate about reflection in the current heterogeneous and rich landscape of philosophy and psychology. However, a productive dialogue between these two essential perspectives can be very useful, in order to better understand both the normative and 
generative aspects of human cognition and action. Both perspectives touch the core of human cognitive and its relation to our daily practices in a social world. We think that the philosopher, the psychologist, the jurist and the social scientist will benefit from the discussion unfolding in the chapters.

\subsubsection{Epistemic Agency and Reflective Scrutiny}

Following Aristotelian inspiration, the work of Sosa (1991) led to a shift in the focus of epistemological investigation. The classical analysis of knowledge used to focus on the nature of belief. Sosa instead maintained that epistemology should focus on the character and virtues of the agent. So, this approach became known as virtue epistemology. In "belief-based" epistemology, the beliefs are the primary object of the epistemic evaluation, the fundamental concepts are "knowledge", "justification" and "justified belief". In its turn, in virtue epistemology, the primary object of the epistemic evaluation are the agents, their character and performances. In this case, the crucial concepts are persons" "capabilities", "powers", "competences", "disposition", "acquired habits", "expertise", that contribute to the successful achievement of their cognitive goals."

Sosa's virtue epistemology $(2007,2009)$ provides a new perspective to the disputes that monopolized the epistemological debates of the 1960s and 1980s, between, on the one hand, foundational and coherentist theories about epistemic justification and, on the other hand, externalist and internalist conceptions about the nature of knowledge. ${ }^{4}$ These foundational and coherentist, externalist and internalist positions address aspects relevant to our cognitive lives, however, their defenders are inclined to refute other positions, even when they contain intuitively relevant ideas: can we set aside the idea that we are natural beings and that the way in which we are embedded in the natural world plays a constitutive role in our mental lives? Can we also reject the idea that reflection and a broad understanding of our cognitive achievements play a central role in our lives? Sosa offers a solution to these disputes.

From Knowledge in Perspective (Sosa 1991) to Reflective Knowledge: Apt Belief and Reflective Knowledge (Sosa 2009), Sosa defends a bi-level epistemology based on a distinction between animal knowledge (AK) and reflective knowledge (RK). ${ }^{6}$ In Sosa (1985, p. 240) the following distinction is established:

(AK) One has animal knowledge about one's environment, one's past, and one's own experience if one's judgments and beliefs about these are direct responses to their impact - e.g., through perception or memory - with little or no benefit of reflection or understanding.

(RK) One has reflective knowledge if one's judgment or belief manifests not only such direct response to the fact known but also understanding of its place in a wider whole that includes one's belief and knowledge of it and how these come about.

These definitions undergo later refinements, but the general meaning remains. Beliefs are a special case of performance, epistemic performances: when a true belief is attributed to the subject's competence under the appropriate conditions, this count as an apt belief and as a kind of knowledge, animal knowledge (Sosa 2007, p. 93). An agent has animal knowledge if his belief is apt, in other words: a) the belief is true (it achieves its objective), b) if the belief is the manifestation of the subject's skills, c) if the belief is true because it arises from the subject's competence; then he does not arrive at the truth by accident (Sosa 2007, p. 92).

Reflective knowledge, on the other hand, is knowledge acquired as the result of the rational epistemic agent's intentional and conscious investigation. Reflective knowledge requires not only apt belief but also defensible apt belief, in other words, an apt belief in which the subject aptly believes that it is apt and where the subject's aptness may be defended against skeptical objections (Sosa 2007, p. 24). While animal knowledge only requires that a belief is true, reflective knowledge additionally requires that the agent have an epistemic perspective "from which he endorses the source of that belief, from which he can see that source as reliably truth-conducive" (Sosa 2009, p. 135).

In the first case (AK), one may talk of "animal competence", since it does not require the cognitive agent to strive "to endorse the reliability of the competence" in the same way, nor does it "require the believer to endorse 
the appropriateness of the conditions for the exercise of the competence in forming that belief." (Sosa 2011, pp. 149-50). In the second case (RK), one may talk of reflective justification, rather than justification only arising from reliability. The (RK) case requires a rational endorsement of the reliability of the competence exercised by the agent and the "appropriateness of the conditions for its exercise" (Sosa 2011, p. 15). In these terms, reflective knowledge goes beyond animal knowledge (Sosa 2007, p. 108).

In this perspective, reflection is not necessary for knowledge in its most basic or animal sense. We know animally even when we are not apt to justify and to present reasons in favor of our knowledge. However, in a scenario of epistemic evaluation, when the subject is challenged to assess the status of their beliefs in the light of epistemic values, when it is necessary to declare that one's belief is true, competent, safe, coherent etc., in the face of skeptical objections (Sosa 2009, pp. 136-7), it is necessary for the epistemic agent to undertake a cognitive performance which is able to endorse the source of this belief and guarantee its reliability, forming a meta-apt or fully apt belief (Sosa 2011, p. 10).

This, according to Sosa, is what characterizes the knowledge problem in the epistemological tradition from Sextus to Descartes. Thus, from the point of view of epistemic evaluation:

Apt belief, animal knowledge, is better than belief that succeeds in its aim, being true, without being apt. Apt belief aptly noted, reflective knowledge, is better than mere apt belief or animal knowledge, especially when the reflective knowledge helps to guide the first-order belief so that it is apt. (Sosa 2011, pp. 12-13)

The reflective knowledge 'that p' is epistemically better than the stand-alone animal knowledge 'that p' because "the safer, better justified, and more reliably acquired beliefs constitute better knowledge" (Sosa 2009, p. 136). However, in Judgment and Agency the distinction between animal and reflective knowledge gives way to a sharper distinction between animal knowledge and knowing full well. This is because knowing full well necessarily involves reflective knowledge. This is due to the fact that our "rational nature is most fully manifest in such reasoned choice and judgment" (Sosa 2015, p. 51). An epistemic performance is fully apt - and not merely apt - if this performance is guided towards aptness through the agent's reflectively apt risk assessment, examining his own competency and aptness.

The chapters of the first section of the volume try to establish a frank and constructive dialogue with these ideas. The second part of the book introduces instead the perspective of cultural psychology on the complex and ongoing question of the different levels of psychological experience. Psychology is indeed dealing with different dimension of psychological phenomena. The meaning of psychological events seems indeed to emerge from complex interaction between levels of systemic organization (the embodied self, the unconscious and presemiotic production of meaning, the first-order experience, the reflective and finally the social). Each of the levels feeds into the other. While generally the different branches of psychology tends to take into account each level separately, the challenge of cultural psychology is exactly to understand the articulation and mutual relationships between the levels.

\subsubsection{Psychological Experience and Reflection}

According to the review by Van Seggelen-Damen et al. (2017), there are at least three different approaches toward reflection in contemporary psychology:

- reflection as self-awareness. In this approach, the investigation of personal knowledge structures by means of introspection is emphasized (Mann et al. 2009; Procee 2006).

- reflection as self-reference. This approach considers the self-other relationships as relevant in reflection. It considers reflection as a process of evaluation of self-reference with respect to the evaluation of the others and by the others, rather than reflection as critical activity (Gürtner et al. 2007; Van Woerkom and Croon 2008). 
- reflection as self-inquiry. This approach focuses on "epistemic" interests and value of reflection. It is interested in the self-questioning assumptions one previously has taken for granted (Livengood et al. 2010; Trapnell and Campbell 1999).

Van Seggelen-Damen et al. (2017) also stress the preoccupation of psychology with the empirical study of reflection. Because of the epistemological paradox above mentioned, psychology cannot trust first person reports without constraining them into allegedly controlled procedures of production and measurement of reflection.

Valsiner (2017) claims that, in the very end, any method in psychology requires the research subject to perform but a controlled and constrained act of introspection. The introspective act consists of "self-observation of internal processes. It presupposes conscious inner perception and can refer to feelings, thoughts, ideas, memories, sensations and perceptions. It can arise unintentionally or spontaneously or be brought about arbitrarily." (Burkart 2018, p. 169) Initially, introspection in psychology derived directly from reflection, as for Brentano (1874/2012) internal perception of one's own mental processes was the main starting point for psychology. Later on, introspection became the main method of the Würzburg School (1896-1909), where the typical experimental setting included a test supervisor and an introspecting test person. The test person had to be a researcher trained in self-observation, usually employees of the institute (Burkart 2018). The test person was presented with complex and everyday tasks and was initially supposed to deal silently with thinking tasks that the research director had given them.

Examples are of questions were: "Can you get to Berlin in seven hours from here?" or "Can we grasp the essence of thought with our thinking?" (Bühler 1907/1999, p. 163) The test supervisor would then ask something like "do you understand?" and the test person would answer "no" or "yes" and then exploring her own process of thinking, under the guidance of the experimenter. This method was later considered "unscientific" because too subjective by an experimental psychology striving for the recognition as positive science. However, the introspective method of the nineteenth century has never been a pure subjective one. It was actually a complex social situation of dialogue between researcher and participant (Tateo 2015).

Other approaches later claimed that it does not exist something as a person thinking about her own psychological processes alone. The socio-constructivist (Pfadenhauer and Knoblauch 2019) and dialogical (Marková 2016) approaches maintain that psychic life emerges from social relationships, to the extent that any inner-dialogue is a dialogue with an internalized social other. The persons, ideas, music, norms, values we encounter in social life become part of our society of the Self (Hermans 2002). They constitute a polyphony of inner voices, representing different internalized social positions, that constantly develop a dialogue when we talk to ourselves.

There are some attempts to bring together the introspective and the intersubjective forms to access psychic experience by developing a method of dialogical introspection (Burkart 2018). The method aims at the exploration of the conscious content of experience (inner processes such as feelings, thoughts, intentions and ideas, both current and remembered) through a group discussion led by a research coordinator (Burkart 2018). The main idea is that subsequent rounds of small group discussions allow the elaboration, interpretation, control and reliability of the introspective materials. In this last approach, one can see the attempt to articulate the relationships between the levels of psychological experience. The person is at the same time subject and object of psychological life. The body is at the same time percipient and mean of perception. The collectively coordinated activities, the social, is at the same time the arena of experience and the frame for the meaning. All these interactions between levels set the frame for the reflective move. Reflection is a dialogical process, to the extent that the voice of the other and my own voice as "other" are necessary conditions to build both a relationship and a differentiation. Without this "inclusive separation" (Valsiner 2017, p. 102), no reflective move and no articulation between levels of the Psyche system would be possible.

\subsection{A Map to the Book}

Chapters are organized in the following way: the first section collects five philosophical texts, four of which discussing the problem of reflection in relation to the influential arguments of Ernest Sosa. The fifth chapter, 
"'Philosophical Reflection and Rashness" by Plínio J. Smith, is not directly reacting to Sosa's philosophy and to contemporary epistemology. Smith presents indeed a larger picture of the relationship between reflection and philosophical investigation as prolegomena to the second section of the book.

The second section is composed of four chapters that try to provide an overview of the rich theoretical production in cultural psychology. The authors focus on the articulation between different levels of the Psyche: the body, the self, the other and the group. Any of these dimensions is characterized by being both subject and object, producer and product of the human psychological experience and the action in the world. What is particularly evident is the variety and the frontier nature of the cultural references provided. It is a main characteristic of cultural psychology that of looking for a constant dialogue between disciplines and worldviews. We will now provide details about the single chapters in the two sections.

\subsubsection{Philosophical Reflectiveness}

In the first chapter, "Animal versus Reflective Orders of Epistemic Competence”, Ernest Sosa presents one of the central themes of his Virtue Epistemology. Differently from epistemological tradition, according to Sosa, judgment and knowledge itself are forms of intentional action or performance, not just simple psychological states. This type of intentional action includes a certain normative structure of success, competence and aptness, or success that manifests competence. In his chapter, Sosa focuses on the notion of competence as a disposition or ability to succeed when one tries, as for instance the competence to drive safely on a given road. Therefore, an epistemic competence is a disposition (capability) to be successful when trying to reach an epistemic good (such as truth, knowledge, etc.). In this sense, in his bi-level epistemology, one can talk about first-order competences and second-order competences. The "animal knowledge" is a belief whose truth shows a first-order competence of the believer (e.g. to perceive a body or to remember an event). Instead, "reflective knowledge requires more of one's first-order apt belief, which now must also manifest a second-order competence, the believer's secondorder competence to judge whether first-order belief is or would be apt" (Sosa, Chap. 2, this volume). A subject's reflective competences resides in the ability to judge, and judgment is both the act of affirming something with an intention and the disposition to consciously judge. Without falling back into vicious regress, reflection is required in judgment, because the agent who judges affirms fully aptly only if guided to a correct and apt affirmation by second-order awareness of their competence to so affirm.

Christoph Kelp, in the chapter "The Status of Reflection in Virtue Epistemology", examines the arguments of Ernest Sosa about the role of reflection in epistemology. He claims that the main normative thesis of Sosa (that the ultimately desirable status for performances in general is the full aptness) can be subject of the objection of overintellectualisation of epistemic processes. ${ }^{7}$ Kelp proposes a way to safeguard Sosa's perspective from this objection: to replace the Normative Thesis (NT), expressing the idea of full aptness, with the thesis that the ultimately desirable state of performances in general is the Simple Normative Thesis (SNT), stating that the fully desirable status for performances in general is (simple first-order) aptness. The central point is that the Simple first-order aptness does not require reflective competence. Therefore, (SNT) allows us to remain on the side of Sosa's virtue epistemology, by dealing with human knowledge as a type of judgment, which is not subject to skepticism and to the flaws of epistemic performances, without necessarily recurring to meta-epistemic performances. In other words, despite Kelp accepts the relevance of Sosa's epistemology, he does not acknowledge that Sosa's arguments can re-appreciate the place of reflection in epistemology. According to Kelp, virtue epistemologists must still agree that reflection has been dethroned in epistemology.

In the third chapter, "The Social Value of Reflection", John Greco recognizes that reflection, understood as metacognitive activity, has been a recurring theme in philosophy. However, he argues against the idea that reflection is necessary to the attribution of knowledge to an individual. On the contrary, Greco thinks that a metacognitive requirement can turn knowledge unachievable, impossible for an individual. Even though, Greco maintains that reflection has a (relevant) epistemic value: it represents an argument in favor of the idea that the primary value of metacognitive activity is social. The reflective act (thinking about our own thinking) contributes to our capability of intellectual cooperation: in practice, how to plan, coordinate, execute and assess the activities with the others. In his chapter, Greco also deals with the topic of epistemic agency. If it is true that human 
agency requires both conscious and self-controlled thinking, it is implausible to attribute conscious and selfdirected thinking to any instance of genuine agency. The question is: how does is possible that conscious and self-directed thinking is a requirement for human action, while it is not a requirement for every individual act of agency? According to Greco, human agency is a social agency. It thus requires relevant capabilities both for conscious thinking and for second-order thinking in the process of interacting with other persons during cooperative tasks.

In "Disagreement, Intellectual Humility and Reflection", Duncan Pritchard explores the theme of reflection starting from an intellectual virtue: the intellectual humility in scenarios of disagreement between epistemic peers, that is disagreements between epistemic agents that are in a position which is not expressing any epistemic advantage over the interlocutor. ${ }^{8}$ For Pritchard, answering to a disagreement with an epistemic peer by an attitude rather than conciliation (i.e., a downgrading of one's conviction in the contested proposition) is incompatible with the requirements of intellectual humility. Intellectual humility requires reflection: "What is certainly true is that encountering an epistemic peer disagreement requires one to reflect on the nature of one's epistemic standing with regard to the target proposition" (Pritchard, Chap. 5, this volume). Thanks to this, [e]ngaging in reflection in this way is how one avoids the intellectual vice of dogmatism" (Pritchard, Chap. 5, this volume). Pritchard contends that, in case of an epistemic performance in scenarios of disagreement, it is virtuous when the agent reflects upon the epistemic position towards the target proposition. It is worth noting that such a reflection is not to be understood as incompatible with the fact that the agent continues believing in the target proposition. A virtuous and reliable understanding of intellectual humility is reasonably compatible with the act of keeping the original judgment.

The last chapter of the first section, "Philosophical Reflection and Rashness", by Plínio Junqueira Smith, does not directly deal with Sosa's approach to reflection within contemporary epistemology. It does not present a theory of reflection either. The chapter rather focuses on the philosophical reflection and on the nature of philosophical investigation, mainly referring to Pyrrhonian skepticism. ${ }^{9}$ Following a Pyrrhonian precept, Smith begins with the idea that the most important confrontation in philosophy is the conflict between skeptics and dogmatics. The chapter starts by explaining the terms of the conflict between skeptics and dogmatics. Thereafter, Smith describes the philosophical investigation as a type of reflection with two complementary sides: on the one side, philosophers reflect upon ordinary thinking, trying to produce a better worldview; on the other side, philosophers reflect upon the philosophical outcomes of the former reflection. Smith suggests that, as both skeptics and dogmatics strive for the truth in philosophical investigation, they do it suing different types of abilities under different conditions. In this sense, one can say that there is a skeptic reflection and a dogmatic reflection, about commonsense beliefs as well as about philosophical beliefs. In the final part of the chapter, Smith claims the superiority of a skeptic attitude, also called Neopyrrhonism. According to Smith, the Pyrrhonist is sincerer in relation to the philosophic requirements of impartiality and rationality, while dogmatics get sometimes away from it. This is the reason for the skeptic still charges dogmatic with recklessness, as the latter interrupts his investigation too early. A decisive point, extremely frequent in literature, is that the skeptic looks to suspend the judgment while at the same time investigating the truth. The baseline is that, in the case of the Pyrrhonist skeptic, the tranquility is not a product of philosophical investigation, rather one of its conditions.

With the concept of "tranquility", we introduce a clearly psychological notion. Psychology is indeed the place of articulation between different levels. Here, reflection is not understood as a metacognitive process. It is a rather complex question of thinking about oneself, of recognizing the affective dimensions of such thinking, but also become reflective about one's affects. It means becoming aware of inhabiting one's own body, but also of the body as an agent of knowledge. Reflection, finally, means to consider humans as agents, but also as colonized agents, as both producer and products of social relationships and normatively guided unique personal trajectories, of historical conditions and of personal history. All these aspects converge into the question of meaning-making, which constitutes the object of the second section of this volume.

\subsubsection{Psychological Reflectiveness}


The second section of the book is opened by the chapter of Robert E. Innis, "Between Feeling and Symbolization: Philosophical Paths to Thinking about Oneself". Innis is a perfect example of the frontier vision of cultural psychology. As philosopher, semioticians, phenomenologist and cultural psychologist, he rotates the different facets of reflection in human life. He discusses a large number of views that converge towards his idea of reflection as a dialogue with oneself. Such a dialogue points in two directions: it turns towards an inner infinity, exploring the realm of self-knowledge; and towards an outer infinity, looking at the right categories that mediate our understanding of what we are and what we do. This twofold activity is historically situated in a double sense: it is the history of my own development (where I am and how I did get there, and where I will be in the future) in the arena of the historical development (the social and historical context of my being). These fourfold directions constantly feed into each other, as in the case of spirituality, in which the most personal and deepest infinities of my self can converge on the unspeakable categories of universal infinity, that I can feel but not verbalize. One of the most intriguing questions raised by Innis is indeed the relationship between signs and reflection in human experience.

The second chapter by Shogo Tanaka, "Bodily origin of self-reflection and its socially extended aspects", provides a relevant reflection about the embodied nature of reflection. One can say that philosophy has sometimes overlooked the fact that we do not just have a body, rather we are bodies. Besides, as Tanaka shows discussing the concepts of phenomenology, humans create through the body the dialogical relationship of subject/object/mean with the world. This relationship is the stem of reflection as well as of social interactions. Tanaka stresses a fundamental contribution of cultural psychology to epistemology: the ambivalent and ambiguous dimension of psychological experience. Ambiguity is not a condition of unachieved knowledge, it is rather the dynamic element of knowing. Ambivalence and ambiguity are inherent to the embodied nature of the self in the world. Thus, a theory of reflection must also incorporate the open-ended aspects of Psyche, as they are suggested by psychological investigation.

The third chapter of the second section, "Psychological reflection, thought and imagination as epistemic skills", by Miika Vähämaa, discusses a different angle of the relationship between social epistemology and cultural psychology. In a way or another, reflection cannot but rely on language, yet language is a historically situated phenomenon. Therefore, Vähämaa asks, what does it happen in our times when language and the capability of a shared ground for virtuous human relationships, the common sense, is subject to radical changes? Reappreciating a concept of common sense that dates back at least to Giambattista Vico, Vähämaa proposes the idea of epistemic skills enhanced by imagination and group support in order to empower the persons' reflective competences (Vähämaa 2018). Reflection is not only a matter of formal logic, but it is also about the capability of accessing multiple logics (e.g. common sense logic, affective logic, imaginative e logic) that enable us to feel virtuous members of our community. In other words, the chapters dialogues with the idea of virtues as characteristics of the agent in relation to a moral dimension. Thus, if we can become more virtuous epistemic agent it will also be thanks to the development of the skill to be better members of our group and to contribute, through reflection, to the betterment of the group itself: the original meaning of the concept of "common sense".

The volume ends with the chapter "Mirrors and Reflexive processes: From looking oneself in the mirror to sensemaking one's own experience. Insidious paths between semiotics, cultural psychology and dynamic psychology" by Raffaele De Luca Picione. Using the metaphor of the mirror, the chapter provides a thoughtful and exhaustive overview of the theoretical and epistemological open question about reflection in cultural psychology and therapy. The reflecting Psyche indeed implies the capability to recognize itself as subjective position in the first person and in relationship with otherness. This generates a self-image, based on an epistemic perspective that cannot coincide with the experience of the world. Which image is more faithful? My own selfimage or the image that is mirrored by the world? What kind of means I have to assess it?

De Luca Picione suggests that, first of all, the reflection process does not produce a static image. The example of therapy is a clear illustration of the fact that reflection is not a solipsistic process. One can think about therapy as the frame in which the self-reflection process is guided by specific techniques. Besides, the chapter reminds us that reflection implies a dynamic overcoming of the present time, integrating the thinking into a temporal 
perspective. The here and now of my thoughts and actions is always in relation to a past, reformulating memory processes, and to a future of expectations, plans and imaginative processes.

\subsection{Conclusions}

What is the place and value of reflection in people's lives? The answer requires a careful discussion about the relationship between our epistemic performances, our intellectual capabilities and competencies, our affective relationships with the environment, our actions and our interpersonal interactions. It is a fact that for us to navigate and interact with the world and with our society, we sometimes think about our reasons, we give reasons, we change our minds, and even think about our habits and character traits in order to make them virtuous. And it seems that at least most of the times, it is by reflection that we do it.

This volume is meant to be a starting point, an invitation to reflection, rather than a dogmatic statement about a closed theory. We think that the first step towards reflection is the open-minded and critical attitude. As the exchange between philosophy, epistemology, and cultural psychology has shown, thinking about reasons, generating knowledge, giving reasons, thinking about oneself and acting are not independent activities. They are rather sub-parts of an open system, dynamically interacting and feeding one into the other. The work of the philosophers and psychologists in this book aims to show that even though these activities can be studied individually by each specialization field, an interdisciplinary work is essential to focus on what connects each other, in this case, on reflection.

Yet, it is not possible in only one volume try to answer all the questions about reflection and explains its complete role in our lives. But we hope that, after reaching the end of this volume, we have triggered some intellectual curiosity and some positive thought about the need for cultivating dialogue beyond boundaries.

\section{Acknowledgments}

The editors are grateful to the institutions that provided intellectual and material support to the making of this volume. Waldomiro Silva Filho thanks the CNPq (Brazil) for the research grant "Bolsa de Produtividade em Pesquisa (\#312111/2016-9)", the CAPES (Brazil) for the international senior visiting grant (BEX 2706/15-6) at Massachusetts Institute of Technology (MIT, Cambridge, MA), as visiting researcher between 2015 and 2016. $\mathrm{He}$ is also grateful to CONCEPT (Cologne Center for Contemporary Epistemology and the Kantian Tradition) of Universität zu Köln (Cologne, Germany) that had him as visiting professor between 2017 and 2018. The idea of this book originated during the visiting at MIT, under the supervision of Prof. Agustin Rayo and the courses of Prof. Alex Byrne. The period at CONCEPT was useful for the final organization of the book and, for these reasons, a special thanks is due to Prof. Sven Bernecker and to Felipe Rocha, his principal interlocutor. Finally, Silva Filho is grateful to the Department of Philosophy at Universidade Federal da Bahia (UFBA) for creating the institutional conditions allowing his periods of leave in order to accomplish research staying abroad. Luca Tateo is grateful to the Universidade Federal da Bahia (UFBA) for hosting his research stays as an international visiting professor, during which he has had the opportunity to establish a very fruitful dialogue between Europe and Brazil and between cultural psychology and a number of other disciplines.

Felipe Rocha L. Santos contributed to this introduction and he is grateful to the Department of Philosophy at Universidade Federal da Bahia (UFBA), for hosting him in the postdoctoral fellowship program PNPD (Programa Nacional de Pós-Doutorado), and also to CONCEPT (Cologne Center for Contemporary Epistemology and the Kantian Tradition) of Universität zu Köln (Cologne, Germany), where he has been visiting scholar between June and August 2017.

\section{References}

\section{AQ5}

Baehr, J. 2008. Four varities of character-based virtue epistemology. The Southern Journal of Philosophy 46: 469-502. 
Bahr, A., and M. Seidel, eds. 2016. Ernest Sosa: Targeting his philosophy. Dordrecht: Springer.

Battaly, H. 2008. Virtue epistemology. Philosophy Compass 3: 639-663.

Bett, R., ed. 2010. The Cambridge companion to acient scepticism. Cambridge: Cambridge University Press.

Bonjour, Laurence. 1985. The structure of empirical knowledge. Cambridge, MA: Harvard University Press.

- - . 1998. In defense of pure reason. Cambridge: Cambridge University Press.

Brentano, F. 1874/2012. Psychology from an empirical standpoint. London: Routledge.

Bühler, K. 1907/1999. Tatsachen und Probleme zu einer Psychologie der Denkvorgänge. I. Über Gedanken. Archiv für die gesamte Psychologie 9: 297-365. [Nachdruck in: Ziche, P. (Ed.). (1999). Introspektion. Texte zur Selbstwahrnehmung des Ichs (pp. 157-209). Berlin: Springer].

Burkart, T. 2018. Dialogic introspection: A method of investigating experience. Human Arenas 1 (2): 167-190. h ttps://doi.org/10.1007/s42087-018-0027-5.

Chisholm, R.M. 1973. The problem of criterion. Milwaukee: Marquette University Press.

- - . 1989. Theory of knowledge. 3rd ed. Englewood Cliffs: Prentice-Hall.

Christensen, D., and J. Lackey. 2013. The epistemology of disagreement. New York: Oxford University Press.

Doris, J.M. 2015. Talking to our selves: Reflection, ignorance, and agency. Oxford: Oxford University Press.

Dunning, D. 2005. Self-insight: Roadblocks and detours on the path to knowing thyself. New York: Psychology Press.

Engel, P. 2013. Is epistemic agency possible? Philosophical Issue, Epistemic Agency 23: 158-178.

Feldman, R., and T. Warfield. 2010. Disagreement. New York: Oxford University Press.

Frances, B. 2014. Disagreement. Cambridge: Polity.

Frankfurt, H. 1971. Freedom of the will and the concept of a person. In The importance of what we care about Philosophical papers, 11-25. Cambridge: Cambridge University Press., 1988.

-.- 1999. The faintest passion. In Necessity, volition, and love. New York: Cambridge University Press.

Goldman, A. 1979. What is justified belief? In Liaisons: Philosophy meets the cognitive and social sciences, 105-126. Cambridge, MA: Bradford., 1992.

Greco, J., ed. 2004. Ernest Sosa and his critics. Malden: Blackwell.

- - - . 2013. Reflective knowledge and the pyrrhonian problematic. In Virtuous thoughts: The philosophy of Ernest Sosa, ed. J. Turri, 179-191. Dordrecht: Springer.

Gürtner, A., F. Tschan, N.K. Semmer, and C. Nägele. 2007. Getting groups to develop good strategies: Effects of reflexivity interventions on team process, team performance, and shared mental models. Organizational 
Behavior and Human Decision Processes 102: 127-142. https://doi.org/10.1016/j.obhdp.2006.05.002.

Hermans, H.J. 2002. The dialogical self as a society of mind: Introduction. Theory \& Psychology 12 (2): 147160 .

Hieronymi, P. 2014. Reflection and responsibility. Philosophy \& Public Affairs 42 (1): 3-41.

Kahneman, D. 2011. Thinking, fast and slow, 2013. New York: Farrar, Straus and Giroux.

Kornblith, H., ed. 2001. Epistemology: Internalism and externalism. Oxford: Blackwell.

- - 2002. Knowledge and its place in nature. Oxford: Oxford University Press.

- - . 2012. On reflection. Oxford: Oxford University Press.

Korsgaard, C. 1996. The sources of normativity. Cambridge: Cambridge University Press.

- - - 2008. Self-constitution: Agency, identity, and integrity. Oxford: Oxford University Press.

Kvanvig, J.L. 2003. The value of knowledge and the pursuit of understanding. Cambridge: Cambridge University Press.

Livengood, J., J. Sytsma, A. Feltz, R. Scheines, and E. Machery. 2010. Philosophical temperament.

Philosophical Psychology 23: 313-330. https://doi.org/10.1080/09515089.2010.490941.

Mann, K., J. Gordon, and A. MacLeod. 2009. Reflection and reflective practice in health professions education: A systematic review. Advances in Health Science Education 14: 595-621. https://doi.org/10.1007/s10459-007-9 090-2.

Marková, I. 2016. The dialogical mind: Common sense and ethics. Cambridge: Cambridge University Press.

Marsico, G., R. Andrisano Ruggieri, and S. Salvatore, eds. 2015. Reflexivity and psychology. Charlotte, NC: Information Age.

Matheson, J. 2015. The epistemic significance of disagreement. London: Palgrave Macmillan.

Mayr, E. 2011. Understanding human agency. Oxford: Oxford University Press.

McDowell, J. 1994. Mind and world. Cambridge, MA: Harvard University Press.

Nagel, Thomas. 1996. Universality and the reflective self. In The sources of normativity, ed. Christine Korsgaard, 200-209. Cambridge: Cambridge University Press.

Pfadenhauer, M., and H. Knoblauch, eds. 2019. Social constructivism as paradigm? London: Routledge.

Plato. 1997. Complete works. Indianapolis: Hackett Publishing Co.

Procee, H. 2006. Reflection in education: A Kantian epistemology. Educational Theory 56: 237-253. https://doi. org/10.1111/j.1741-5446.2006.00225.x.

Proust, J. 2013. The philosophy of metacognition: Mental agency and self-awareness. Oxford: Oxford University 
Press.

Ransome, W. 2009. Moral reflection. New York: Palgrave Macmillan.

Sextus Empiricus (HP). 2000. Outlines of Scepticism (Hipotiposes Pirronianas - Pyrrōneioi Hypotypōeis). Trans. \& ed. Julia Anna and Jonathan Barnes. Cambridge: Cambridge University Press.

Silva Filho, W.J., and F.S. Rocha. 2015. Reflection, epistemic value and human flourishing. Analytica 19 (1): $129-144$.

Skorupski, J. 2010. The domain fo reasons I. Oxford: Oxford University Press.

Sosa, E. 1985. Knowledge and intellectual virtue. In Knowledge in perspective: selected essays in epistemology, 225-244. Cambridge: Cambridge University Press., 1991.

- - . 1991. Knowledge in perspective: Selected essays in epistemology. Cambridge: Cambridge University Press.

- - . 2007. A virtue epistemology. Vol. I. Oxford: Oxford UP.

- - . 2009. Reflective knowledge. Vol. II. Oxford: Oxford UP.

- - - 2011. Knowing full well. Princeton/Oxford: Princeton University Press.

- - . 2013. Pyrrhonian skepticism and human agency. Philosophical Issue 23: 1-17.

- - - 2014. Epistemic agency and judgment. In Epistemic norms: News essays on action, belief, and assertion, ed. J. Turri and C. Littlejohn, 173-191. Oxford: Oxford University Press.

- - . 2015. Judgement and agency. Oxford: Oxford University Press.

- - . 2017. Epistemology. Princeton/London: Princeton University Press.

Tateo, L. 2015. Gulliver's eggs: Why methods are not an issue of qualitative research in cultural psychology. Integrative Psychological and Behavioral Science 49 (2): 187-201.

Tiberius, V. 2008. The reflective life: Living wisely with our limits. Oxford: Oxford UP.

Trapnell, P.D., and D.T. Campbell. 1999. Private self-consciousness and the five-factor model of personality: Distinguishing rumination from reflection. Journal of Personality and Social Psychology 76: 284-304. https://do i.org/10.1037/0022-3514.76.2.284.

Turri, J., ed. 2013. Virtuous thoughts: The philosophy of Ernest Sosa. Dordrecht: Springer.

Vähämaa, M. 2018. Common sense, language, and semantic primes: Liminal or constant concepts of psychology? Human Arenas 1 (3): 305-320. https://doi.org/10.1007/s42087-018-0014-x.

Valsiner, J. 2015. The purpose of purpose. In Jerome S. Bruner beyond 100: Cultivating possibilities, ed. G. Marsico, 79-86. New York: Springer.

- - - 2017. From methodology to methods in human psychology. New York: Springer. 
Valsiner, J., Marsico, G., Chaudhary, N., Sato, T., \& Dazzani, V. (Eds.) (2016). Psychology as the science of human being. The Yokohama manifesto. Cham: Springer International Publishing.

Van Seggelen-Damen, I.C.M., R. Van Hezewijk, A.S. Helsdingen, and J.I.G. Wopereis. 2017. Reflection: A socratic approach. Theory and Psychology 27 (6): 793-814. https://doi.org/10.1177/0959354317736388.

Van Woerkom, M., and M. Croon. 2008. Operationalizing critically reflective work behavior. Personnel Review 37: 317-331. https://doi.org/10.1108/00483480810862297.

Zagzebski, L.T. 1996. Virtue of the mind: An inquiry into the nature of virtue and the ethical foundations of knowledge. Cambridge: Cambridge University Press.

There is a rich literature about the moral aspect of reflection. In this volume, we focus on the epistemological aspects. About the moral perspective, see Korsgaard (2008) and Ransome (2009). Mayr (2011) and Doris (2015) discuss a criticism of reflectivism. Kornblith (2012) provides a critical literature overview of different aspects of the current debate about reflection.

2 Besides, there is disagreement about the relationship between being an agent of one's own actions, responsible for these actions, and being an epistemic agent, responsible for one's own beliefs. Pascal Engel (2013) writes: "there is a limit to any claim that we can be epistemic agents, which is that the structure of reasons for epistemic attitudes differs fundamentally from the structure of reasons for actions" (p. 158).

3 Authors such as Zagzebski (1996) and Kvanvig (2003) developed different versions of virtue epistemology, usually known as responsibilist virtue epistemology. About the different versions of virtue epistemology, see Baehr (2008) and Battaly (2008).

4 For a full overview of the debate, see Kornblith (2001)

5 Some of the topics developed in the following paragraphs also appear in Silva Filho and Rocha (2015).

6 In Judgment and Agency (Sosa 2015), Sosa talks about something inferior to animal knowledge (subcredal animal knowledge) and considers various degrees, up to the maximum human degree, which is knowing full well; here it is possible to conceive not two, but three levels of knowledge: animal, reflective and full. We will not address this point here.

This objection is mainly applied to the classic internalism (e.g. Chisholm 1973, 1989) in epistemology, that maintains that only the subject, having conscious access to the reasons to believe, can actually know.

8 One of the central questions of the epistemology of disagreements (accepting that this is a rational disagreement) is: what should be done when one is aware of disagreement - continue to believe the initial belief, renounce the belief or suspend judgment. The main publications that provide an overview of this discussion are Feldman and Warfield (2010), Christensen and Lackey (2013), Frances (2014), and Matheson (2015).

9 About Pyrrhonian skepticism, see Sextus Empiricus (2000). An overview of ancient skepticism can be found in Bett (2010). 